\title{
E-cigarettes and English exceptionalism
}

\author{
Martin McKee', David Bareham² \\ 'London School of Hygiene \& Tropical Medicine, London, UK \\ 'Lincolnshire Community Health Services NHS Trust, Beech House, Witham Park, Waterside South, Lincoln, UK
}

\begin{abstract}
ADDRESS FOR CORRESPONDENCE: Martin McKee, London School of Hygiene \& Tropical Medicine, 15-17 Tavistock Place, London, WC1H 9SH, UK, e-mail: martin.mckee@lshtm.ac.uk
\end{abstract}

In the accompanying paper, Professor Gruszczyński reflects on the differing views about the European Union Tobacco Products Directive for e-cigarettes [1]. As he notes, there are some who see them as a means to end the smoking epidemic, while others view them as an instrument that is being used by the traditional tobacco industry to thwart this objective. He concludes that, given the continuing uncertainty about these products, the Directive is an appropriate response. We agree.

We would, however, add one important observation to his thoughtful review of the arguments being made by health organisations. Those whom he quotes as in favour of relaxing restrictions on e-cigarettes and, in some cases, even argue that they be promoted actively, are from one country, England. Yet even there, support for e-cigarettes is far from universal. Thus, the National Institute for Health and Clinical Excellence (NICE), which evaluates evidence on effectiveness of treatments, does not recommend them as cessation aids [2].

Elsewhere in Europe, and indeed also in other parts of the United Kingdom, concerns are widespread and are growing, for several reasons. First, there is growing evidence that these products promote nicotine addiction among young people, with some suggestion that this may be slowing or even reversing the long-term decline in smoking initiation [3]. Second, it has so far been impossible to find high-quality evidence that they increase cessation rates, with much of the available evidence suggesting they reduce them [4]. Third, evidence of their health risks is accumulating, especially in relation to lung and cardiovascular disease [5]. And finally, there are concerns about the enormous resources being used by the tobacco industry to promote them, and in particular the role of the Philip Morris-funded Foundation for a Smoke-Free World [6-8], coupled with the promotion of new products in the British markets designed to maximise nicotine delivery [9], as well as reports that e-cigarette manufacturers are emulating tactics traditionally associated with the tobacco industry [10].

There is particular concern about the now widely cited claim by Public Health England that e-cigarettes are "95\% safer" than traditional cigarettes. As has been reported previously, this figure is based not on empirical data but on a meeting of individuals, some with links to e-cigarette manufacturers [11], whose report conceded that the evidence was insufficient to reach a robust conclusion [12]. Serious questions have been raised about the funding and organisation of this meeting [13]. The $95 \%$ safer figure has been repeatedly used by a small number of English organisations, justified only by the argument that the authors of their various reports have reviewed the evidence and agree with it [14]. This view is, however, far from universal even in England, with one team of respiratory physicians who have documented the adverse effects of e-cigarettes on lung function stating that "If we persist in the approach of Public Health England with its disregard for protecting the respiratory health of adolescents and young children, we are risking a further epidemic of devastating lung disease for today's children" [15], while two leading toxicologists have described Public Health England's promotion of e-cigarettes as "a reckless and irresponsible decision" [16].

European organisations have also been much more sceptical about the claimed benefits of e-cigarettes. The European Respiratory Society, responding to a paper in the British Medical Journal supporting the use of e-cigarettes [17], stated that "no-one, expert or otherwise, can credibly assert that e-cigarettes are safer than tobacco in the long term, given that they contain a whole new tranche of unregulated and unstudied compounds being inhaled into the lung" [18]. The European Heart Network also supports a cautious approach, advocating similar measures on marketing and price that have been effective in reducing smoking prevalence [19]. The European Public 
Health Association has stated that "It is not possible, at this point, to make any claims about the relative safety of e-cigs compared to traditional cigarettes. The overall effect may well be to worsen the tobacco epidemic first by deflecting smokers from using proven smoking cessation strategies and shifting them to e-cigs, which, for most smokers, reduce successful smoking cessation, and second by deflecting discussion from measures opposed by the tobacco industry" [20].

As with Brexit, a decision widely viewed as incomprehensible in the rest of Europe, some in England demonstrate a strong sense of exceptionalism in their attitude to e-cigarettes, as if the evidence from other countries does not apply to them. In both of these cases, some people seem willing to engage in an experiment on the health of the population. Others, meanwhile, will wait and learn from their experience.

\section{DISCLOSURE}

The authors report no conflict of interest.

\section{References}

1. Gruszczyński L. The EU regime for e-cigarettes: A rationale compromise or regulatory failure? J Health Inequalities 2018; 4: 62-67.

2. NICE. Stop smoking interventions and services. Guidance and guidelines. NICE, 2018. Available from: https://www. nice.org.uk/guidance/ng92/chapter/recommendations\#evidence-based-stop-smoking-interventions (accessed: 9 December 2018).

3. Chapman S, Bareham D, Maziak W. The Gateway Effect of e-cigarettes; Reflections on main Criticisms. Nicotine Tob Res 2018 Apr 6.

4. Glantz SA, Bareham DW. E-Cigarettes: Use, Effects on Smoking, Risks, and Policy Implications. Annu Rev Public Health 2018; 39: 215-235.

5. Alzahrani T, Pena I, Temesgen N, Glantz SA. Association Between Electronic Cigarette Use and Myocardial Infarction. Am J Prev Med 2018; 55: 455-461.

6. Daube M, Moodie R, McKee M. Towards a smoke-free world? Philip Morris International's new Foundation is not credible. Lancet 2017; 390: 1722-1724.

7. Thomas DP, Hefler M, Bonevski B, et al. Australian researchers oppose funding from the Foundation for a Smoke-Free World. Aust N Z J Public Health 2018; 42: 506-507.

8. van der Eijk Y, Bero LA, Malone RE. Philip Morris International-funded, Foundation for a Smoke-Free World': analysing its claims of independence. Tob Control 2018 Sep 21; pii: tobaccocontrol-2018-054278.

9. Mathis W. BAT Launches High-Tech Vape in U.K. to Fend Off Juul, IQOS. T12:49:11.745Z 2018. Available from: https://www. bloomberg.com/news/articles/2018-12-11/bat-launches-hightech-vape-in-the-u-k-to-fend-off-juul-iqos (accessed: 11 December 2018).

10. Forster M. JUUL Takes a Page from Big Tobacco. 2018. Available from: https://www.eastbayexpress.com/oakland/juul-takes-
a-page-from-big-tobacco/Content?oid=23476179 (accessed: 9 December 2018).

11. Gornall J. Public Health England's troubled trail. BMJ 2015; 351: h5826.

12. Nutt DJ, Phillips LD, Balfour D, et al. Estimating the harms of nicotine-containing products using the MCDA approach. Eur Addict Res 2014; 20: 218-225.

13. McKee M, Capewell S. Evidence about electronic cigarettes: a foundation built on rock or sand? BMJ 2015; 351: h4863.

14. Britton J, Arnott D, McNeill A, Hopkinson N, Physicians TAGotRCo. Nicotine without smoke - putting electronic cigarettes in context. BMJ 2016; 353: 11745 .

15. Bush A, Bhatt J, Grigg J. E cigarettes: Tar Wars: The (Tobacco) Empire Strikes Back. Arch Dis Child 2018 Nov 29; pii: archdischild-2018-315820.

16. Combes RD, Balls M. A critical assessment of the scientific basis, and implementation, of regulations for the safety assessment and marketing of innovative tobacco-related products. Altern Lab Anim 2015; 43: 251-290.

17. Hartmann-Boyce J, Begh R, Aveyard P. Electronic cigarettes for smoking cessation. BMJ 2018; 360: j5543.

18. European Respiratory S. "We have not learned:" ERS leaders respond to $\mathrm{BMJ}$ article on the use of e-cigarettes for smoking cessation. Eur Respir Soc 2018. Available from: https://www. ersnet.org/the-society/news/we-have-not-learned:-ers-leaders-respond-to-bmj-article-on-the-use-of-e-cigarettes-forsmoking-cessation (accessed: 9 December 2018).

19. Available from: https://www.rcplondon.ac.uk/file/3563/download?token=Mu0K_ZR0 (accessed: 15 November 2018).

20. EUPHA. Facts and fiction on e-cigs. 2018. Available from: https://eupha.org/repository/advocacy/EUPHA_facts_and_ fiction_on_e-cigs.pdf (accessed: 10 December 2018).

\section{AUTHORS' CONTRIBUTIONS}

MM, DB prepared the research concept, wrote the article and approved the final version of the publication. 